\title{
Nasal high-flow versus noninvasive ventilation in patients with chronic hypercapnic COPD
}

This article was published in the following Dove Press journal:

International Journal of Chronic Obstructive Pulmonary Disease

\author{
Jens Bräunlich (D) \\ Dominic Dellweg (iD) ${ }^{2}$ \\ Andreas Bastian (iD ${ }^{3}$ \\ Stephan Budweiser ${ }^{4}$ \\ Winfried Randerath ${ }^{5}$ \\ Dora Triché6 \\ Martin Bachmann ${ }^{7}$ \\ Christian Kähler ${ }^{8}$ \\ Abdel Hakim Bayarassou ${ }^{9}$ \\ Irmhild Mäder ${ }^{10}$ \\ Jens Geiseler "I \\ Norbert Köhler (D) ${ }^{12}$ \\ David Petroff (iD ${ }^{12}$ \\ Hubert Wirtz' \\ 'Department of Respiratory Medicine, \\ University of Leipzig AöR, Leipzig, Germany; \\ ${ }^{2}$ Fachkrankenhaus Kloster Grafschaft $\mathrm{GmbH}$, \\ Schmallenberg Grafschaft, Germany; \\ ${ }^{3}$ Pneumologie/Intensivmedizin/Infektiologie, \\ Marienkrankenhaus Kassel, Kassel, Germany; \\ ${ }^{4}$ Medizinische Klinik III, RoMed Klinikum \\ Rosenheim, Rosenheim, Germany; \\ ${ }^{5}$ Krankenhaus Bethanien gGmbH, Klinik für \\ Pneumologie und Allergologie, Zentrum für \\ Schlaf- und Beatmungsmedizin, Solingen, \\ Germany; ${ }^{6}$ Department of Respiratory \\ Medicine, Allergology and Sleep Medicine, \\ Paracelsus Medical University Nuernberg, \\ General Hospital Nuernberg, Nürnberg, \\ Germany; ${ }^{7}$ Intensivmedizin und \\ Beatmungsmedizin, Klinik für Atemwegs-, \\ Lungen- und Thoraxmedizin, Asklepios \\ Klinikum Harburg, Hamburg, Germany; \\ ${ }^{8}$ Department of Internal Medicine, Innsbruck \\ Medical University, Innsbruck, Austria; ${ }^{9}$ Klinik \\ für Pneumologie, Kardiologie, Schlaf- und \\ Beatmungsmedizin, Malteser Krankenhaus \\ Seliger Gerhard, Bonn/Rhein-Sieg, Bonn, \\ Germany; ${ }^{10}$ Zentralklinik Bad Berka GmbH, \\ Klinik für Pneumologie, Bad Berka, Germany; \\ 1 'Medizinische Klinik IV, Klinikum Vest - \\ Paracelsus-Klinik Marl, Marl, Germany; \\ ${ }^{12}$ Clinical Trial Centre Leipzig, University of \\ Leipzig, Leipzig, Germany
}

Correspondence: Jens Bräunlich

Department of Respiratory Medicine,

University of Leipzig AöR, Liebigstrasse 20,

Leipzig 04103, Germany

Tel +4934I 971 2450

Email highflow@web.de
Background: Despite the encouraging results of noninvasive ventilation (NIV) in chronic hypercapnic COPD patients, it is also evident that some patients do not tolerate NIV or do not benefit from it. We conducted a study in which COPD patients with stable, chronic hypercapnia were treated with NIV and nasal high-flow (NHF) to compare effectiveness.

Methods: In a multi-centered, randomized, controlled, cross-over design, patients received 6 weeks of NHF ventilation followed by 6 weeks of NIV ventilation or vice-versa (TIBICO) between 2011 and 2016. COPD patients with stable daytime hypercapnia $\left(\mathrm{pCO}_{2} \geq 50 \mathrm{mmHg}\right.$ ) were recruited from 13 German centers. The primary endpoint was $\mathrm{pCO}_{2}$ changes from baseline blood gas, lung function, quality of life (QoL), the 6 min walking test, and duration of device use were secondary endpoints.

Results: A total of 102 patients (mean $\pm \mathrm{SD}$ ) age $65.3 \pm 9.3$ years, $61 \%$ females, body mass index $23.1 \pm 4.8 \mathrm{~kg} / \mathrm{m}^{2}, 90 \%$ GOLD D, $\mathrm{pCO}_{2} 56.5 \pm 5.4 \mathrm{mmHg}$ were randomized. $\mathrm{PCO}_{2}$ levels decreased by $4.7 \%$ ( $\mathrm{n}=94$; full analysis set; $95 \%$ CI 1.8-7.5, $P=0.002)$ using NHF and 7.1\% (95\% CI 4.1-10.1, $P<0.001)$ from baseline using NIV (indistinguishable to intention-to-treat analysis). The difference of $\mathrm{pCO}_{2}$ changes between the two devices was $-1.4 \mathrm{mmHg}(95 \% \mathrm{CI}$ $-3.1-0.4, P=0.12$ ). Both devices had positive impact on blood gases and respiratory scores (St. George's Respiratory Questionnaire, Severe Respiratory Insufficiency Questionnaire).

Conclusions: NHF may constitute an alternative to NIV in COPD patients with stable chronic hypercapnia, eg, those not tolerating or rejecting NIV with respect to $\mathrm{pCO}_{2}$ reduction and improvement in QoL.

Keywords: noninvasive ventilation, nasal high-flow, COPD, hypercapnia

\section{Introduction}

Noninvasive ventilation (NIV) is the standard therapy for ventilatory failure in acute exacerbation of COPD. Increasing evidence of its effectiveness has been generated for more than two decades. ${ }^{1}$ Studies have demonstrated a rapid improvement in blood gases as well as the reduction of respiratory rate, frequency of intubation, length of hospital stay, and mortality. ${ }^{2}$

Recent trials have shown that NIV also benefits COPD patients with chronic hypercapnia. $^{3-5}$ A multi-center study with 195 stable hypercapnic COPD patients revealed that NIV decreases 1-year mortality. ${ }^{3}$ A further study confirmed reduced mortality and additionally showed reduced rates of exacerbation and hospital readmission. ${ }^{4}$ Other parameters improved by NIV include hypercapnia, oxygen saturation, respiratory rate, dyspnea, 6-min walking test (6MWT)-distance, and quality of life (QoL). ${ }^{3,5-10}$ Despite these encouraging results, it is also evident that some patients do not tolerate NIV or do not benefit from it. ${ }^{9,11-13}$ 
Nasal high-flow (NHF) provides warmed and humidified gas administered through slightly enlarged nasal prongs. Oxygen fraction can be adjusted according to clinical requirements. Near-saturated humidity and gas warmed to body temperature allow tolerance of high flow rates. NHF results in only small increases of airway pressure, further reduced by opening the mouth. ${ }^{14} \mathrm{NHF}$ reduces minute volume, lowers respiratory rate, and decreases work of breathing. ${ }^{15-18}$ The exhaled gas in the upper airways is rapidly washed out, and thus physiological dead-space is reduced. ${ }^{19,20}$ The high flow rates delivered by NHF are sufficient to cover even high peak inspiratory flows, thereby avoiding the admixture of ambient air. ${ }^{21}$

In a recent study, NHF was found to be superior to standard nasal prongs (SNP) and NIV in patients with severe hypoxemic respiratory failure with regard to intubation rate and mortality. ${ }^{22}$ Reintubation rates with NHF were lower than ${ }^{23,24}$ or non-inferior ${ }^{25}$ compared to either venturi mask, SNP or NIV, respectively.

In addition, there is mounting evidence that NHF leads to a reduction in partial pressure of $\mathrm{CO}_{2}\left(\mathrm{pCO}_{2}\right)$ reduction in hypercapnic patients over short periods. ${ }^{15,26-29}$ NHF was also successful in reducing $\mathrm{pCO}_{2}$ in a small pilot trial for 6 weeks. ${ }^{27}$ Together with $\mathrm{CO}_{2}$ wash-out studies ${ }^{19,27}$ these results led us to hypothesize that NHF might benefit chronic hypercapnic COPD patients.

To test this hypothesis, we conducted a study in which COPD patients with stable, chronic hypercapnia were treated in a cross-over design with NIV and NHF for 6 weeks each. The primary endpoint was $\mathrm{pCO}_{2}$ reduction compared to baseline.

\section{Materials and methods Study subjects}

COPD patients with chronic respiratory insufficiency and stable daytime hypercapnia $\left(\mathrm{pCO}_{2} \geq 50 \mathrm{mmHg}\right)$ were recruited from 13 hospitals in Germany. Patients were excluded if they had a type I or II exacerbation ${ }^{30}$ within the last 4 weeks, had been treated with NIV during the last 14 days, or if their body mass index was higher than $30 \mathrm{~kg} / \mathrm{m}^{2}$. The full list of inclusion and exclusion criteria can be found in the Supplementary materials (section 2). All patients were at least 18 years of age and provided written informed consent. The study was conducted in accordance with the Declaration of Helsinki. Local institutional review boards or independent ethics committees approved the protocol, and written informed consent was obtained from all patients (Ethical Committee at the Medical Faculty, Leipzig University 123/09-ff). The trial registered with clinicaltrials.gov (NCT02007772).

\section{Study design}

NHF and NIV were compared in a multi-centered, randomized, controlled, 12-week cross-over trial (randomized controlled trial; RCT) (6 weeks with each device, see Supplementary materials [section 1]). The primary goal was to provide an estimate of the difference between the devices regarding $\mathrm{pCO}_{2}$ change.

\section{Methods}

Patients were randomly assigned to receive either NHF or NIV first. Randomization was performed centrally by the Clinical Trial Center Leipzig using block randomization with variable block length, stratified by trial site.

For NHF, we used the TNI 20 oxy and nasal prongs with medium bore outlets (TNI Medical AG, Wuerzburg, Germany). A flow rate of $20 \mathrm{~L} / \mathrm{min}$ was stipulated by the study protocol and oxygen supplementation was not changed compared to baseline (spontaneous breathing with oxygen by nasal cannula). At the time of study inception, NHF devices did not delivered $>20 \mathrm{~L} / \mathrm{min}$.

All centers were instructed to follow the German guidelines for humidification and NIV pressure settings. It was the general aim to adjust pressures to achieve optimal tolerability and $\mathrm{pCO}_{2}$ reduction. ${ }^{31}$ The preferred interface was an oronasal mask, but a nasal mask could be used in case of intolerance. Trial sites were free to choose their preferred NIV (listed in Table S1).

Patients were advised to use NIV and NHF for at least $6 \mathrm{hrs}$ per day, preferably during sleep, but usage in the daytime was also accepted. Duration of ventilation was based on the devices' usage data.

\section{Analysis}

The primary endpoint was the change in $\mathrm{pCO}_{2}$ between baseline and the end of the NIV or NHF treatment. The secondary endpoints were changes in capillary blood gases, lung function, 6MWT, QoL and compliance (see Supplementary materials [section 4]).

The rationale that motivated this trial was intrinsically the non-inferiority of NHF. Because of the paucity of data and lack of consensus regarding margins of equivalence in this context, we chose descriptive estimates for the primary analysis and a non-inferiority test as a secondary analysis. The sample size determination followed accordingly. Based on an 
expected SD of $11 \%$ in paired differences taken from pilot data, a sample size of 70 patients was required to have a $95 \%$ CI spanning a width of $6 \%$ of the baseline value (difference in paired means, coverage corrected, nQuery 6.02). Taking drop-out into account, a recruitment of 100 patients was planned for this study. A test of non-inferiority of NHF with a margin of $5 \mathrm{~mm} \mathrm{Hg}$ was specified in the statistical plan as a secondary analysis, based on mean treatment effects from two trials available at the time. ${ }^{3,32}$

The full analysis set (intention to treat) included all patients who started treatment and had $\mathrm{pCO}_{2}$ values $\geq 50 \mathrm{~mm} \mathrm{Hg}$ at screening and no $<45 \mathrm{~mm} \mathrm{Hg}$ at baseline. The per protocol set includes essentially those patients that received both devices and used them sufficiently (see Supplementary materials [section 3] for a precise definition).

Missing data were accounted for using multiple imputation (see Supplementary materials [section 4]). Outcomes were analyzed with a mixed model for repeated measures with the patient as a random variable. The difference between NHF and NIV devices was estimated along with a $95 \%$ CI. In one sensitivity analysis, the same mixed model was applied to nonimputed data. In a second sensitivity analysis, the trial center was included as a random term. A paired $t$-test was used to compare the duration of device usage. For data analysis and graphic presentation, we used the software package $\mathrm{R}$ (version 3.4.1).

\section{Results}

\section{Patients}

From May 2011 until November 2016, 102 patients were randomized, 94 of whom were included in the intention to treat analysis (Figure 1). Since the $\mathrm{pCO}_{2}$ levels of five randomized patients $\left(\mathrm{pCO}_{2} \geq 50 \mathrm{mmHg}\right.$ at screening decreased to below $45 \mathrm{mmHg}$ at baseline, the indication for treatment was no longer given. Three further patients withdrew from the trial before receiving the first treatment.

The per protocol set contained 53 patients with similar demographic characteristics and baseline $\mathrm{pCO}_{2}$ values to the full analysis set. Baseline characteristics are presented in Table 1, and list of concomitant diseases and medications can be found in Tables S2 and S3. All patients had no history of any lasting NIV treatment, but all were on longterm oxygen therapy.

\section{Treatments}

A total of 91 patients began NHF treatment with a flow rate of $19.8 \pm 0.6 \mathrm{~L} / \mathrm{min}$ and $\mathrm{O}_{2}$ insufflation of $2.2 \pm 0.9 \mathrm{~L} / \mathrm{min}$ and
82 patients began NIV treatment with an oronasal mask (57), with a nasal mask (21), or with both (1). Three patients did not tolerate NIV very early on and terminated use within the first $24 \mathrm{hrs}$. An additional 11 patients terminated use of NIV early, six for device related, four for disease-related and one for study-related reasons. Sixteen patients terminated use of NHF early, six for device related, five for disease-related and five for study-related reasons. Mean inspiratory and expiratory positive airway pressures (IPAP and EPAP) were $20.5 \pm 3.6 \mathrm{~cm} \mathrm{H}_{2} \mathrm{O}$ and $4.6 \pm 1.2 \mathrm{~cm}$ $\mathrm{H}_{2} \mathrm{O}$ respectively, $\mathrm{O}_{2}$ rate was $2.0 \pm 0.7 \mathrm{~L} / \mathrm{min}$ and $13.3 \pm 3.9$ breaths/min for those in $\mathrm{S} / \mathrm{T}$ mode $(\mathrm{n}=73)$.

Data on time used were available for 70 NHF devices (77\%), 54 NIV devices (66\%), and for 47 patients who used both. Mean duration of NHF usage was $5.2 \pm 3.3 \mathrm{hrs} /$ day compared to $3.9 \pm 2.5 \mathrm{hrs} /$ day for NIV. The mean difference for those who used both was $1.6 \mathrm{hrs} /$ day $(95 \%$ CI, 0.9-2.4; $P<0.001$ ) for NHF versus NIV (Figure S1).

\section{Primary and secondary endpoints}

$\mathrm{PCO}_{2}$ levels decreased by $2.8 \mathrm{~mm} \mathrm{Hg}(95 \%$ CI 1.1-4.6) or $4.7 \%$ (95\% CI 1.8-7.5) using NHF and $4.2 \mathrm{~mm} \mathrm{Hg}(95 \%$ CI $2.4-6.0)$ or $7.1 \%$ (95\% CI 4.1-10.1) from baseline using NIV. The difference of $\mathrm{pCO}_{2}$ changes between the two devices was $-1.4 \mathrm{mmHg}(95 \% \mathrm{CI}-3.1-0.4)$, where the minus sign indicates that NIV had a stronger effect (Table 2). This difference lies within the non-inferiority margin of $5 \mathrm{~mm} \mathrm{Hg}, P<0.001$. Sensitivity analyses demonstrated that neither a completer case analysis nor the introduction of a random effect from the centers alters this result meaningfully. In the per protocol set, $\mathrm{pCO}_{2}$ levels decreased by $2.9 \mathrm{mmHg}$ and $4.3 \mathrm{mmHg}$ using NHF and $\mathrm{NIV}$, respectively, and the difference of $\mathrm{pCO}_{2}$ changes between the devices was $-1.3(95 \% \mathrm{CI}-3.0-0.4) \mathrm{mmHg}$ and thus indistinguishable from that of the full analysis set. There was no indication that the order of devices was relevant $(P=0.59)$. Blood samples were taken a median of $7.0 \mathrm{hrs}$ (IQR: 4.6-8.7) after stopping use of the device.

A considerable reduction in $\mathrm{pCO}_{2}(>5 \mathrm{~mm} \mathrm{Hg})$ was reached in $37 \%$ of patients during NHF use and $52 \%$ during NIV use. However, increases in $\mathrm{pCO}_{2}$ were observed in $26 \%$ with NHF and $22 \%$ with NIV (Figure 2). An exploratory analysis of reasons for good/poor response can be found in section 5 of the Supplementary materials.

$\mathrm{PO}_{2}$, spirometry, 6MWT, and QoL are listed in Table 2. Changes from baseline tended to be small for $\mathrm{pO}_{2}$, spirometry, and 6MWT, but were significant and clinically meaningful for QoL. While using NHF, 61\% 


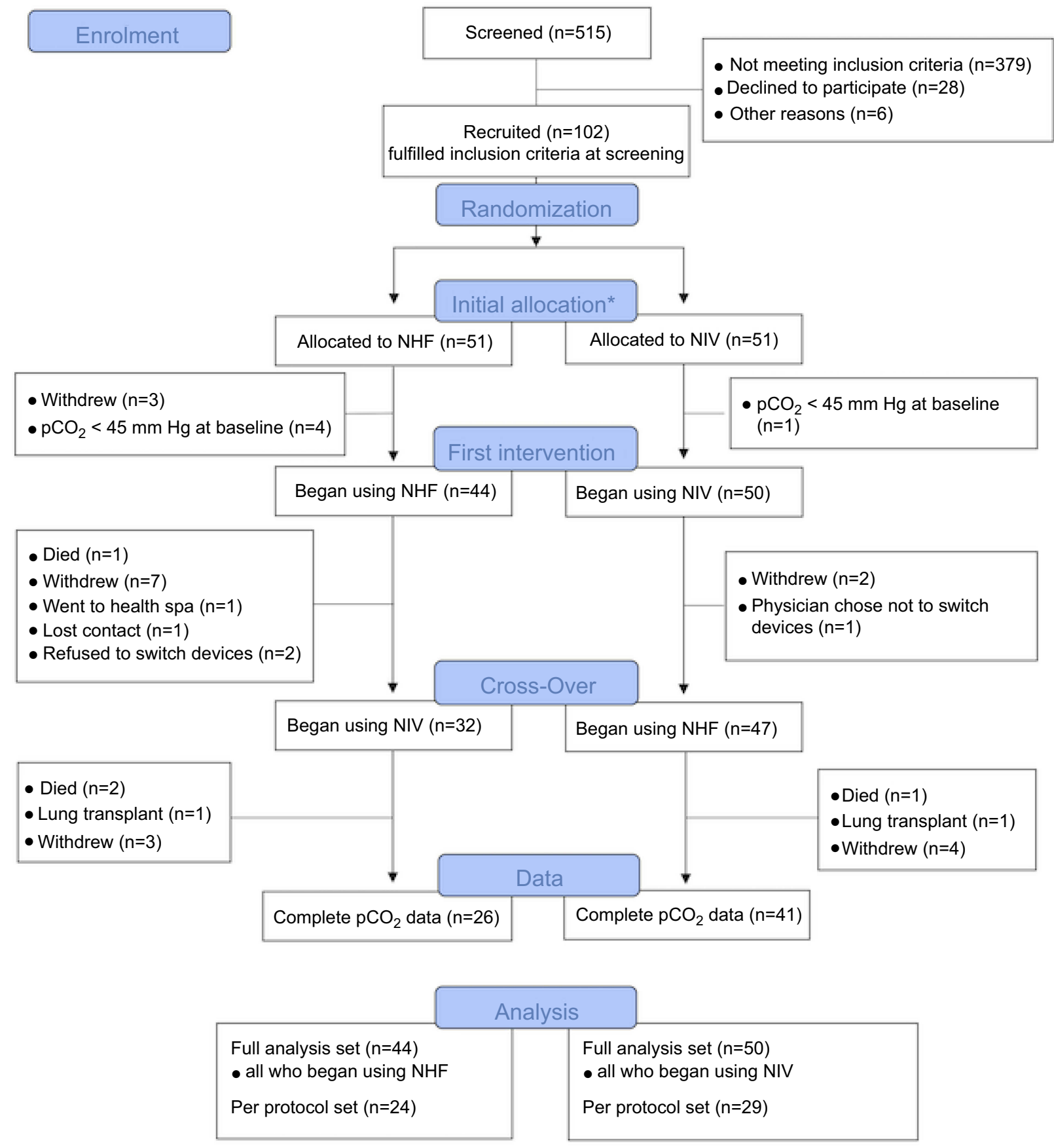

- Due to a mix-up, one patient received the devices in the wrong order.

Figure I Flowchart of enrolment, device usage and patients analyzed.

Abbreviations: NHF, nasal high-flow; NIV, noninvasive ventilation; $\mathrm{PCO}_{2}$, the partial pressure of carbon dioxide in capillary blood.

of patients improved their St. George's Respiratory Questionnairetotal scores by at least 4 points and a similar 54\% while using NIV. Differences in the endpoints listed in Table 2 were not generally significant between NHF and NIV.

\section{Safety}

Four patients died during the trial, two while using NHF and two while using NIV (see Supplementary materials [section 7]). Other adverse events are listed according to the device used upon onset of the event in Table 3. 
Table I Baseline demographic and clinical characteristics

\begin{tabular}{|c|c|}
\hline & $N=94$ \\
\hline Females & $57(61 \%)$ \\
\hline Age (years) & $65.3 \pm 9.3$ \\
\hline BMI $\left(\mathrm{kg} / \mathrm{m}^{2}\right)$ & $23.1 \pm 4.8$ \\
\hline $\mathrm{BMI}<18.5$ & $20(21 \%)$ \\
\hline $\mid 8.5 \leq \mathrm{BMI}<25$ & 37 (39\%) \\
\hline $\mathrm{BMI} \geq 25$ & 37 (39\%) \\
\hline Heart rate (bpm) & $82.3 \pm 12.9$ \\
\hline Six-minute walking test $(\mathrm{m})$ & $236 \pm 135$ \\
\hline Time since COPD diagnosis (years) & 7.1 (3.3 to II.7) \\
\hline Smoking & \\
\hline Current smoker & $19(21 \%)$ \\
\hline Ex-smoker & $69(77 \%)$ \\
\hline Never smoked & $2(2 \%)$ \\
\hline Number of pack years & $40(28$ to $5 \mathrm{I})$ \\
\hline Number of exacerbations in last 12 months $^{a}$ & $1.8 \pm 2.2$ \\
\hline 0 exacerbations & $24(26 \%)$ \\
\hline I-2 exacerbations & $46(51 \%)$ \\
\hline$\geq 3$ exacerbations & $21(23 \%)$ \\
\hline Number with hospital stay & $1.2 \pm 1.6$ \\
\hline CAT score & $24.7 \pm 7.6$ \\
\hline GOLD classification 2011 & \\
\hline $\mathrm{D}$ & $79(90 \%)$ \\
\hline C & $6(7 \%)$ \\
\hline$B$ or $A$ & $3(3 \%)$ \\
\hline $\mathrm{O}_{2}$ insufflation $(\mathrm{L} / \mathrm{min})$ & $2.0 \pm 0.9$ \\
\hline Capillary $\mathrm{pCO}_{2}(\mathrm{mmHg})$ & $56.5 \pm 5.4$ \\
\hline Capillary $\mathrm{pO}_{2}(\mathrm{mmHg})$ & $68.9 \pm 16.0$ \\
\hline $\mathrm{pH}$ & $7.399 \pm 0.036$ \\
\hline Base excess (BE, mmol/L) & $8.4 \pm 3.8$ \\
\hline $\mathrm{HCO}_{3}^{-}(\mathrm{mmol} / \mathrm{L})$ & $32.1 \pm 3.2$ \\
\hline FEV (\% predicted) & $28.5 \pm 10.2$ \\
\hline FVC (\% predicted) & $48.0 \pm 15.0$ \\
\hline $\mathrm{FEV}_{\mathrm{l}} / \mathrm{FVC}(\%)$ & $49.4 \pm 13.4$ \\
\hline Respiratory rate (breaths/min) & $20.7 \pm 5.5$ \\
\hline
\end{tabular}

Notes: Values are numbers (\%), mean SD or median (interquartile range). ${ }^{\mathrm{a} D a t a}$ were unavailable for 3 patients.

Abbreviation: BMI, body mass index.

\section{Discussion}

In this randomized, controlled, multi-centered cross-over trial, NHF was similarly effective to NIV with modest improvements in capillary $\mathrm{pCO}_{2}$ in both groups and a slight tendency in favor of NIV. This is the first RCT providing evidence that NHF is effective in COPD patients with stable chronic hypercapnia.
NHF and NIV reduced capillary $\mathrm{pCO}_{2}$ by $2.8 \mathrm{mmHg}$ (4.7\%) and $4.2 \mathrm{mmHg}$ (7.1\%), respectively. These results for NIV correspond well to those of Köhnlein et al, ${ }^{3}$ who found that capillary $\mathrm{pCO}_{2}$ was lowered by $7.4 \%$ after 1 year of treatment and differed by $5.1 \%$ from the control group. A recent trial by Murphy et $\mathrm{al}^{4}$ observed similar reductions in $\mathrm{pCO}_{2}$ by $6.2 \mathrm{mmHg}$ after 6 weeks.

Most studies on NHF have either excluded hypercapnic patients or studied a population containing both normoand hypercapnic patients and have thus found little or no reduction in $\mathrm{pCO}_{2}{ }^{23-25,33}$ Studies exploring the effect of NHF on $\mathrm{pCO}_{2}$ in purely hypercapnic patients ${ }^{15,16,26-28,34}$ suggest a dependence on the baseline $\mathrm{pCO}_{2}$ value, as might be expected. ${ }^{16,34}$

A recent study compared long-term oxygen therapy (LTOT) with and without NHF in 29 stable hypercapnic COPD patients. NHF inhibited the LTOT-induced increase in $\mathrm{pCO}_{2}$ and improved QoL. ${ }^{35}$ Another recent study demonstrated unaltered lung function in COPD patients during brief NHF use. ${ }^{29}$

In most studies with hypercapnic patients, blood gas samples were taken during NHF treatment or immediately thereafter. ${ }^{15,16,26,27}$ In this trial, blood gases were taken after a minimum of $3 \mathrm{hrs}$ following respiratory support to a) reflect the situation in an outpatient clinic and b) provide data on lasting effects. However, this lag period might result in smaller treatment effects compared to studies with shorter intervals. ${ }^{16,27}$ In a previous, similarly designed pilot study, but without similar delay, we observed a more pronounced $\mathrm{pCO}_{2}$ reduction both with $\mathrm{NHF}$ and $\mathrm{NIV}^{27}$ It is plausible that $\mathrm{pCO}_{2}$ rises during the day after night-time use of respiratory support. The mentioned NIV trials on chronic hypercapnic COPD patients were designed with a 1-hr delay between NIV use and blood gas analysis. ${ }^{3,4}$

Changes in secondary endpoints were very similar between the two devices and suggest effective respiratory support for COPD patients. In particular, improvements in QoL, a well-established benefit of $\mathrm{NIV},{ }^{9}$ were comparable with those of NHF treatment. The respiratory rate was reduced in NHF only. The 6MWT-distance increased with both devices although this was not significant for NHF. Changes in exacerbation rates and rehospitalizations could not be assessed within the 6-week time frame. We present individual patient data on capillary $\mathrm{pCO}_{2}$ as a waterfall plot, demonstrating the large variance in individual response and providing data on the numbers 


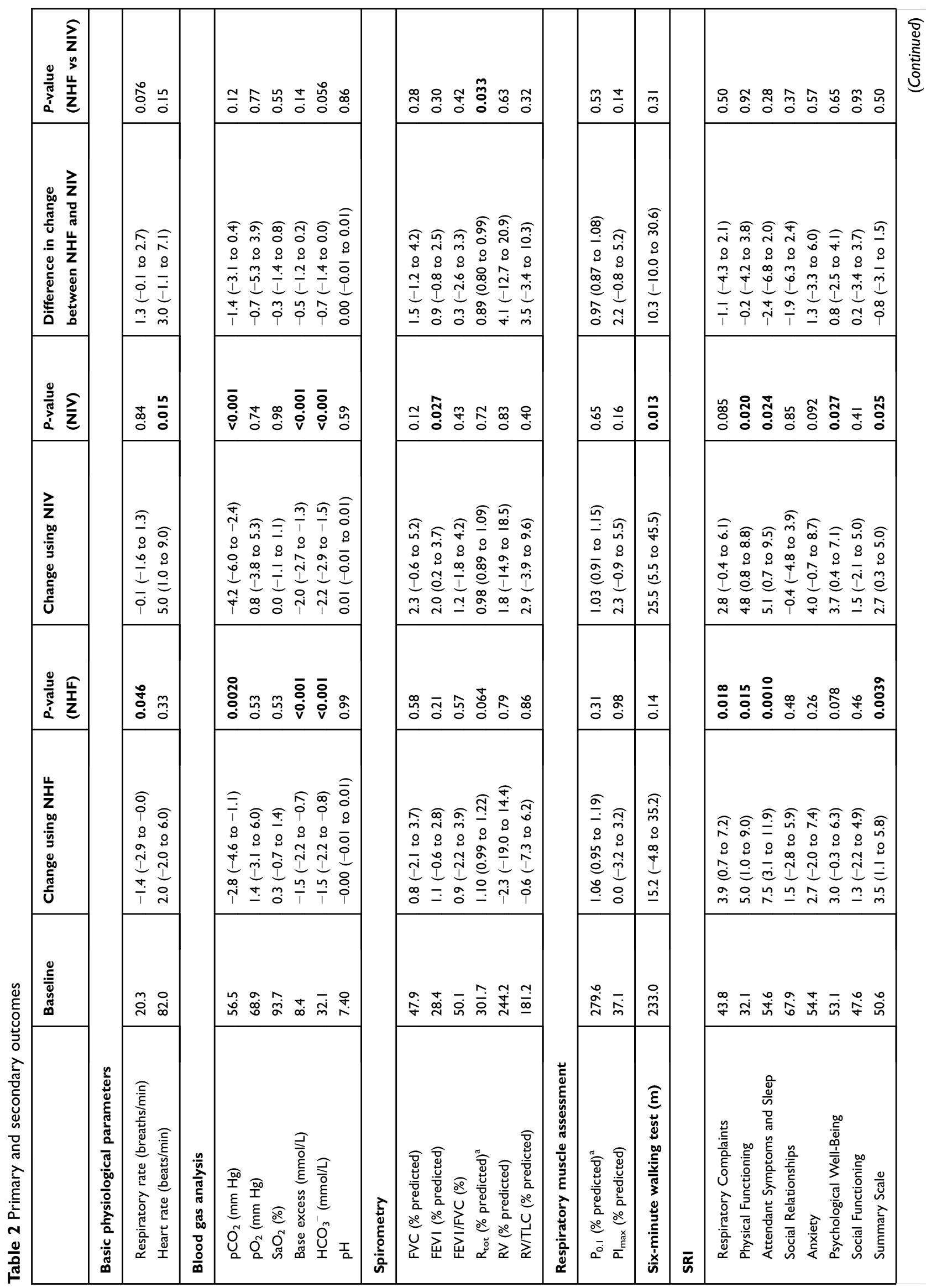




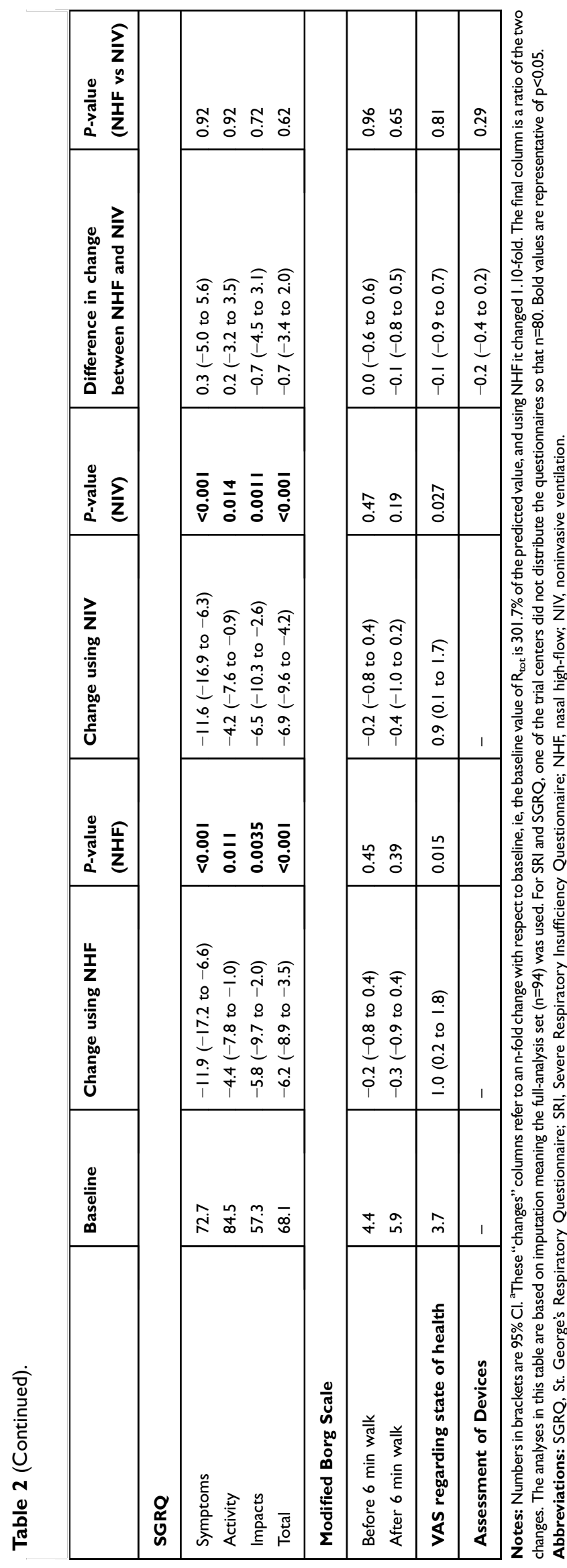

who respond well and poorly. A similar spectrum of responses has not yet been described in a comparably clear fashion, although it has been mentioned in the literature. ${ }^{3,4,11,12,35}$ The SD we observed for $\mathrm{pCO}_{2}$ changes is roughly comparable to that reported in other studies, suggesting that they observed a similar spectrum of responses.

Many clinicians would agree that not every patient will benefit from NIV. However, there are only few dependable criteria for predicting success. ${ }^{3,4,11-13,16,32}$ We found nonresponders in roughly comparable numbers using both devices. Exploratory analyses showed that a variety of demographic and disease-specific markers were not associated with the extent of the $\mathrm{pCO} 2$ response. A nonnegligible minority of patients had higher levels of $\mathrm{pCO}_{2}$ with ventilatory support compared to the beginning of the study. Such responses might derive from the fact that we performed a "real life" study in which the health of chronically ill patients can deteriorate despite the use of noninvasive respiratory support.

It is important to note that in this study, NHF was administered with a relatively moderate flow of $20 \mathrm{~L} / \mathrm{min}$, which was state of the art at trial conception. This trial demonstrates that NHF with a flow of $20 \mathrm{~L} / \mathrm{min}$ is a good treatment option in stable hypercapnic COPD patients. However, it is likely that treatment with higher flow rates will result in further improvements. ${ }^{16,27}$

An important prerequisite for an effective treatment of COPD patients by NIV is the choice of a sufficient pressure difference combined with respiratory rate control and adequate duration of treatment. ${ }^{3-5,36}$ In this regard, the settings applied in our trial are slightly different from those applied in the studies of Murphy et al (median IPAP $24 \mathrm{cmH}_{2} \mathrm{O}$, EPAP $4 \mathrm{~cm}$ $\mathrm{H}_{2} \mathrm{O}$, respiratory rate $14 / \mathrm{min}$ ) and Köhnlein et al (mean IPAP $21.6 \mathrm{cmH}_{2} \mathrm{O}$, EPAP $4.8 \mathrm{cmH}_{2} \mathrm{O}$, respiratory rate $\left.16 / \mathrm{min}\right) .{ }^{3,4} \mathrm{In}$ our trial, NHF and NIV were used on average for $5.2 \mathrm{hrs} /$ day (data available from $77 \%$ of patients) and $3.9 \mathrm{hrs} /$ day (66\% of patients), respectively. In the study of Köhnlein et al, NIV was used for $5.9 \mathrm{hrs} /$ day ( $47 \%$ of patients). Murphy et al reported a mean use of $4.7 \mathrm{hrs} /$ day ( $84 \%$ of patients) after comparable 6 weeks. When compared to NIV, the longer use of NHF observed in our trial might indicate better tolerance. A number of studies have indeed demonstrated improved comfort of NHF over other devices. ${ }^{16,23,37}$

Earlier studies indicated that NIV is effective at reducing $\mathrm{pCO}_{2}$ only in patients with stable hypercapnia. ${ }^{3,42} \mathrm{In}$ particular, hypercapnia can even be reversible after acute exacerbation $^{32,38}$ and it is uncertain whether or not NIV 


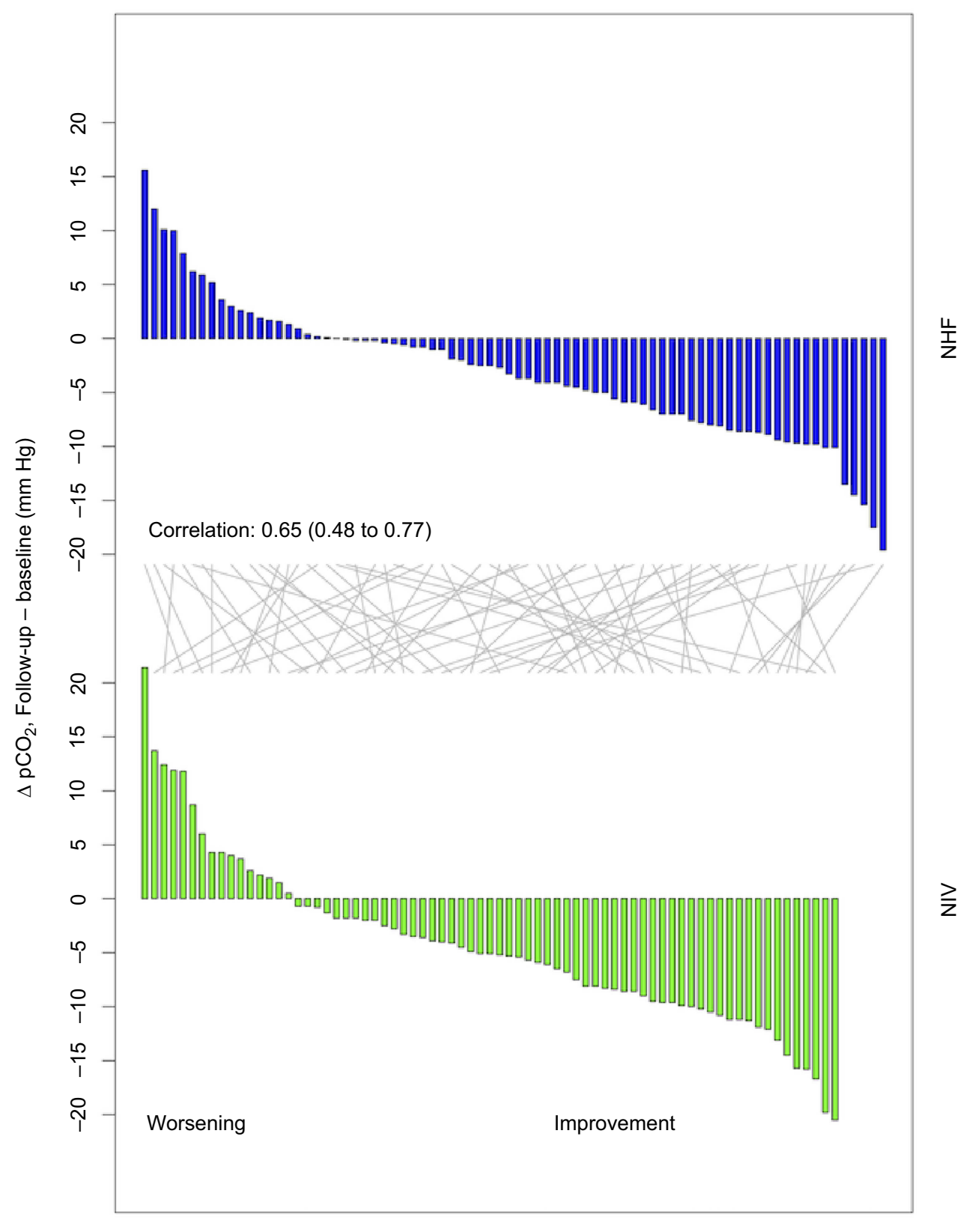

Patients

Figure 2 Waterfall plot depicting the individual change in carbon dioxide levels in capillary blood $\left(\mathrm{pCO}_{2}\right)$ before and after intervention.

Notes: NHF, nasal high-flow; NIV, noninvasive ventilation. $\triangle \mathrm{pCO}_{2}$ is the difference in partial pressures of carbon dioxide in capillary blood between baseline and follow-up. Each bar represents $\Delta \mathrm{pCO}_{2}$ for a single patient and the grey lines show how the patients in the upper and lower halves correspond, ie, the grey line connects a given patient before and after cross-over. The correlation coefficient between changes with NHF and NIV $(95 \% \mathrm{Cl})$ is shown for patients that used both devices.

then has any added benefit. Our minimum 4-week exacerbation-free interval was chosen to exclude transient hypercapnia at the time of inclusion in the study.

Limitations of our study include lower usage times of NIV, slightly lower pressure difference (IPAP-EPAP) compared to previous studies ${ }^{3,4}$ and the use of an NHF device with a restriction of $20 \mathrm{~L} / \mathrm{min}$ flow. This may have influenced the efficacy of the devices. Moreover, the trial was registered after about one-quarter of the patients had been recruited, the data for usage time were incomplete and blinding was not possible. Strengths of this study are the cross over design, the demonstration of a lasting effect and the exclusion of patients with transient hypercapnia following exacerbation. 
Table 3 There were a total of 38 non-lethal SAEs among 21 patients ( 9 only NHF, 8 only NIV, 4 patients with both devices)

\begin{tabular}{|c|c|c|}
\hline & NHF & NIV \\
\hline Death & 2 & 2 \\
\hline Number of SAEs (non-lethal) & 17 & 21 \\
\hline \multicolumn{3}{|l|}{ Respiratory } \\
\hline Dyspnoea & - & I \\
\hline Exacerbation & 11 & 7 \\
\hline Atelectasis & 1 & - \\
\hline Hypercapnic respiratory failure & 1 & - \\
\hline Mechanical ventilation & 1 & I \\
\hline Pneumonia & - & 1 \\
\hline Pneumothorax spontaneous & - & I \\
\hline Pulmonary failure & - & 1 \\
\hline Respiratory acidosis & 1 & - \\
\hline \multicolumn{3}{|l|}{ Cardiac } \\
\hline Myocardial infarction & 1 & - \\
\hline Decompensation & 1 & I \\
\hline Panic attack & & 2 \\
\hline Other & - & 7 \\
\hline Number of AEs (not also SAEs) & 33 & 55 \\
\hline \multicolumn{3}{|l|}{ Respiratory/possibly related to device } \\
\hline Aerophagia & - & 5 \\
\hline Bronchitis acute & 1 & - \\
\hline Claustrophobia & - & I \\
\hline Coldness local & - & I \\
\hline Conjunctivitis & - & 1 \\
\hline COPD exacerbation & 13 & 13 \\
\hline Dyspnoea & - & 3 \\
\hline Ear problem & - & I \\
\hline Epistaxis/nasal dryness/nasal irritation & 5 & 2 \\
\hline Hemoptysis & 1 & - \\
\hline Insomnia & 1 & I \\
\hline Middle ear disorder & 1 & - \\
\hline Oral thrush & 1 & 1 \\
\hline Panic attacks & 1 & I \\
\hline Rib pain & 1 & - \\
\hline \multicolumn{3}{|l|}{ Cardiac } \\
\hline Decompensation & - & 1 \\
\hline Tachycardia & - & I \\
\hline Signs of right-heart failure & 4 & 7 \\
\hline Other & 4 & 16 \\
\hline
\end{tabular}

Abbreviations: SAE, serious adverse event; NHF, nasal high-flow; NIV, noninvasive ventilation.

In summary, we have shown that NHF may well represent an alternative to NIV in chronic hypercapnic COPD patients with comparable effectiveness. Future studies will have to elucidate the question of how $\mathrm{pCO} 2$ reduction may translate into a benefit on survival or other clinical outcomes.

\section{Abbreviations list}

(p) $\mathrm{CO}_{2}$, (partial) pressure of carbon dioxide; (p)O $\mathrm{O}_{2}$, (partial) pressure of oxygen; 6MWT, 6-min walking test; EPAP, expiratory positive airway pressure; IPAP, inspiratory positive airway pressure; LTOT, long-term oxygen therapy; NHF, nasal high-flow; NIV, noninvasive ventilation; QoL, quality of life; RCT, randomized controlled trial; SNP, standard nasal prongs.

\section{Data sharing statement}

The authors will share the statistical analysis plan and study protocol upon request. An online supplement will be available. The data will be available for 5 years. Further data will be shared upon qualified request, in particular for metaanalyses or individual patient meta-analyses. In the latter case, those requesting data will be asked to provide a copy of an institutional review board approval and show that the meta-analysis has been registered in a public registry.

\section{Acknowledgments}

This study was an investigator-initiated project supported by TNI Medical AG through grants and provision of equipment. The sponsor had no role in the design and conduct of the study, the collection, management, analysis and interpretation of the data, the preparation, review or approval of the manuscript, or the decision to submit the manuscript.

\section{Author contributions}

All authors contributed toward data analysis, drafting and revising the paper, gave final approval of the version to be published and agree to be accountable for all aspects of the work.

\section{Disclosure}

Dr. Bräunlich reports grants and non-financial support from TNI Medical AG during the conduct of the study; and grants, personal fees and non-financial support from TNI Medical AG and personal fees from Fisher\&Paykel, outside the submitted work. Prof. Kähler reports non-financial support from TNI Medical AG. Prof. Randerath reports grants from Heinen und Löwenstein, Weinmann, Philips Respironics, and Inspire, outside the submitted work. Prof. Wirtz reports personal fees and non-financial support from TNI Medical AG, during the conduct of the study. All other authors have nothing to disclose. 


\section{References}

1. Brochard L, Isabey D, Piquet J, et al. Reversal of acute exacerbations of chronic obstructive lung disease by inspiratory assistance with a face mask. N Engl J Med. 1990;323(22):1523-1530. doi:10.1056/ NEJM199011293232204

2. Osadnik CR, Tee VS, Carson-Chahhoud KV, Picot J, Wedzicha JA, Smith BJ. Noninvasive ventilation for the management of acute hypercapnic respiratory failure due to exacerbation of chronic obstructive pulmonary disease. Cochrane Database Syst Rev. 2017;7:CD004104. doi:10.1002/14651858.CD003881.pub4

3. Köhnlein T, Windisch W, Köhler D, et al. Noninvasive positive pressure ventilation for the treatment of severe stable chronic obstructive pulmonary disease: a prospective, multicentre, randomised, controlled clinical trial. Lancet Respir Med. 2014;2 (9):698-705. doi:10.1016/S2213-2600(14)70153-5

4. Murphy PB, Rehal S, Arbane G, et al. Effect of home noninvasive ventilation with oxygen therapy vs oxygen therapy alone on hospital readmission or death after an acute COPD exacerbation: a randomized clinical trial. JAMA. 2017;317(21):2177-2186. doi:10.1001/jama.2017.5254

5. Dreher M, Storre JH, Schmoor C, Windisch W. High-intensity versus low-intensity noninvasive ventilation in patients with stable hypercapnic COPD: a randomised crossover trial. Thorax. 2010;65 (4):303-308. doi:10.1136/thx.2009.124263

6. Díaz O, Bégin P, Andresen M, et al. Physiological and clinical effects of diurnal noninvasive ventilation in hypercapnic COPD. Eur Respir J. 2005;26(6):1016-1023. doi:10.1183/09031936.05.00033905

7. Windisch W. Quality of life in home mechanical ventilation study group. Impact of home mechanical ventilation on health-related quality of life. Eur Respir J. 2008;32(5):1328-1336. doi:10.1183/09031936.00066407

8. Budweiser S, Hitzl AP, Jörres RA, Schmidbauer K, Heinemann F, Pfeifer M. Health-related quality of life and long-term prognosis in chronic hypercapnic respiratory failure: a prospective survival analysis. Respir Res. 2007;8(1):1025-1029. doi:10.1186/14659921-8-91

9. Tsolaki V, Pastaka C, Karetsi E, et al. One-year noninvasive ventilation in chronic hypercapnic COPD: effect on quality of life. Respir Med. 2008;102(6):904-911. doi:10.1016/j.rmed.2008.04.008

10. Wijkstra PJ. Noninvasive positive pressure ventilation (NIPPV) in stable patients with chronic obstructive pulmonary disease (COPD). Respir Med. 2003;97(10):1086-1093. doi:10.1016/S0954-6111(03)00163-X

11. Chan VL, Chu C-M. Compliance with home noninvasive ventilation. Respirology. 2012;17(4):735-736. doi:10.1111/j.1440-1843.2012.02169.x

12. Tissot A, Jaffre S, Gagnadoux F, et al. Home noninvasive ventilation fails to improve quality of life in the elderly: results from a multicenter cohort study. PLoS One. 2015;10(10):e0141156. doi:10.1371/journal. pone. 0141156

13. Nava S, Gregoretti C. Interfaces and humidification for noninvasive mechanical ventilation. Respir Care. 2009;54(1):71-84.

14. Parke RL, McGuinness SP, Eccleston ML. A preliminary randomized controlled trial to assess effectiveness of nasal high-flow oxygen in intensive care patients. Respir Care. 2011;56(3):265-270. doi:10.4187/ respcare. 00801

15. Bräunlich J, Beyer D, Mai D, Hammerschmidt S, Seyfarth H-J, Wirtz H. Effects of nasal high flow on ventilation in volunteers, COPD and idiopathic pulmonary fibrosis patients. Respiration. 2013;85(4):319-325. doi:10.1159/000342027

16. Bräunlich J, Köhler M, Wirtz H. Nasal highflow improves ventilation in patients with COPD. COPD. 2016;11:1077-1085. doi:10.2147/COPD

17. Biselli PJC, Kirkness JP, Grote L, et al. Nasal high-flow therapy reduces work of breathing compared with oxygen during sleep in COPD and smoking controls: a prospective observational study. J Appl Physiol. 2017;122(1):82-88. doi:10.1152/japplphysiol.00279.2016
18. Delorme M, Bouchard P-A, Simon M, Simard S, Lellouche F. Effects of high-flow nasal cannula on the work of breathing in patients recovering from acute respiratory failure. Crit Care Med. 2017;45(12):1981-1988. doi:10.1097/CCM.0000000000002693

19. Möller W, Feng S, Domanski U, et al. Nasal high flow reduces dead space. J Appl Physiol. 2017;122(1):191-197. doi:10.1152/ japplphysiol.00584.2016

20. Bräunlich J, Goldner F, Wirtz $\mathrm{H}$. Nasal highflow eliminates $\mathrm{CO}_{2}$ from lower airways. Respir Physiol Neurobiol. 2017;242:86-88. doi:10.1016/j.resp.2017.03.012

21. Wagstaff TAJ, Soni N. Performance of six types of oxygen delivery devices at varying respiratory rates. Anaesthesia. 2007;62(5):492-503. doi:10.1111/j.1365-2044.2007.05026.x

22. Frat J-P, Thille AW, Mercat A, et al. Supplementary appendix: high-flow oxygen through nasal cannula in acute hypoxemic respiratory failure. $N$ Engl J Med. 2015;372(23):2185-2196. doi:10.1056/ NEJMoa1503326

23. Maggiore SM, Idone FA, Vaschetto R, et al. Nasal high-flow versus venturi mask oxygen therapy after extubation. Effects on oxygenation, comfort, and clinical outcome. Am J Respir Crit Care Med. 2014;190(3):282-288. doi:10.1164/rccm.2014020364OC

24. Hernández G, Vaquero C, González P, et al. Effect of postextubation high-flow nasal cannula vs conventional oxygen therapy on reintubation in low-risk patients: a randomized clinical trial. JAMA. 2016;315 (13):1354-1361. doi:10.1001/jama.2016.2711

25. Hernández G, Vaquero C, Colinas L, et al. Effect of postextubation high-flow nasal cannula vs noninvasive ventilation on reintubation and postextubation respiratory failure in high-risk patients: a randomized clinical trial. JAMA. 2016;316(15):1565-1574. doi:10.1001/jama.2016.14194

26. Pisani L, Fasano L, Corcione N, et al. Change in pulmonary mechanics and the effect on breathing pattern of high flow oxygen therapy in stable hypercapnic COPD. Thorax. 2017;72(4):373-375. doi:10.1136/thoraxjnl-2016-209673

27. Bräunlich J, Seyfarth H-J, Wirtz H. Nasal high-flow versus noninvasive ventilation in stable hypercapnic COPD: a preliminary report. Multidiscip Respir Med. 2015;10(1):27. doi:10.1186/s40248-015-0019-y

28. Jeong JH, Kim DH, Kim SC, et al. Changes in arterial blood gases after use of high-flow nasal cannula therapy in the ED. Am $J \quad$ Emerg Med. 2015;33(10):1344-1349. doi:10.1016/j. ajem.2015.07.060

29. Vogelsinger H, Halank M, Braun S, et al. Efficacy and safety of nasal high-flow oxygen in COPD patients. BMC Pulm Med. 2017;17 (1): $1-8$.

30. Anthonisen NR, Manfreda J, Warren CP, Hershfield ES, Harding GK, Nelson NA. Antibiotic therapy in exacerbations of chronic obstructive pulmonary disease. Ann Intern Med. 1987;106(2):196-204. doi:10.7326/0003-4819-106-2-196

31. Windisch W, Walterspacher S, Siemon K, Geiseler J, Sitter H. German society for pneumology. Guidelines for noninvasive and invasive mechanical ventilation for treatment of chronic respiratory failure. published by the german society for pneumology (DGP). Pneumologie. 2010;64(10):640-652. doi:10.1055/s-00301255558

32. Struik FM, Sprooten RTM, Kerstjens HAM, et al. Nocturnal noninvasive ventilation in COPD patients with prolonged hypercapnia after ventilatory support for acute respiratory failure: a randomised, controlled, parallel-group study. Thorax. 2014;69 (9):826-834. doi:10.1136/thoraxjnl-2013-203884

33. Frat J-P, Thille AW, Mercat A, et al. High-flow oxygen through nasal cannula in acute hypoxemic respiratory failure. $N$ Engl $J$ Med. 2015;372(23):2185-2196. doi:10.1056/NEJMoa1503326

34. Bräunlich J, Wirtz H. NHF and hypercapnia: how brief can you look? Respirology. 2017;22(6):1049-1050. doi:10.1111/resp.13092 
35. Nagata K, Kikuchi T, Horie T, et al. Domiciliary high-flow nasal cannula oxygen therapy for stable hypercapnic COPD patients: a multicenter, randomized crossover trial. Ann Am Thorac Soc. 2018;15(4):432-439. doi:10.1513/AnnalsATS.201706-425OC

36. Murphy PB, Davidson C, Hind MD, et al. Volume targeted versus pressure support noninvasive ventilation in patients with super obesity and chronic respiratory failure: a randomised controlled trial. Thorax. 2012;67(8):727-734. doi:10.1136/thoraxjnl-2012-201768
37. Cuquemelle E, Pham T, Papon J-F, Louis B, Danin P-E, Brochard L. Heated and humidified high-flow oxygen therapy reduces discomfort during hypoxemic respiratory failure. Respir Care. 2012;57 (10):1571-1577. doi:10.4187/respcare.01681

38. Costello R, Deegan P, Fitzpatrick M, McNicholas WT. Reversible hypercapnia in chronic obstructive pulmonary disease: a distinct pattern of respiratory failure with a favorable prognosis. Am J Med. 1997;102(3):239-244. doi:10.1016/S0002-9343(97)00017-X

\section{Publish your work in this journal}

The International Journal of COPD is an international, peer-reviewed journal of therapeutics and pharmacology focusing on concise rapid reporting of clinical studies and reviews in COPD. Special focus is given to the pathophysiological processes underlying the disease, intervention programs, patient focused education, and self management protocols. This journal is indexed on PubMed Central, MedLine and CAS. The manuscript management system is completely online and includes a very quick and fair peer-review system, which is all easy to use. Visit http://www.dovepress.com/testimonials.php to read real quotes from published authors. 